\title{
Téoros
}

Revue de recherche en tourisme

\section{Mimoun Hillali, Le tourisme international vu du Sud, PUQ, Québec, 2003}

\section{Marc Laplante}

Volume 22, numéro 3, automne 2003

URI : https://id.erudit.org/iderudit/1071352ar

DOI : https://doi.org/10.7202/1071352ar

Aller au sommaire du numéro

Éditeur(s)

Université du Québec à Montréal

ISSN

0712-8657 (imprimé)

1923-2705 (numérique)

Découvrir la revue

Citer ce compte rendu

Laplante, M. (2003). Compte rendu de [Mimoun Hillali, Le tourisme international vu du Sud, PUQ, Québec, 2003]. Téoros, 22(3), 63-64.

https://doi.org/10.7202/1071352ar

Ce document est protégé par la loi sur le droit d'auteur. L'utilisation des services d'Érudit (y compris la reproduction) est assujettie à sa politique d'utilisation que vous pouvez consulter en ligne.

https://apropos.erudit.org/fr/usagers/politique-dutilisation/
Cet article est diffusé et préservé par Érudit.

Érudit est un consortium interuniversitaire sans but lucratif composé de l’Université de Montréal, l'Université Laval et l'Université du Québec à Montréal. Il a pour mission la promotion et la valorisation de la recherche. https://www.erudit.org/fr/ 


\section{Le tourisme international vu du Sud PUQ, Québec, 2003}

\section{Marc Laplante}

$\mathbf{E}$ n parcourant le livre d'Hillali, le lecteur développera l'intérêt de connaître l'auteur autant que son œuvre. Enseignant et chercheur, Mimoun Hillali est très au fait des recherches sur les rapports entre tourisme et pays en développement. Comme le Maroc est pauvre en moyens de recherche, l'auteur a tenté de tirer tout ce qu'il pouvait des statistiques existantes, mais son livre témoigne surtout de sa grande capacité d'observation et de sa longue fréquentation des agents touristiques des quatre coins de son pays. Sa thèse d'État, La politique touristique marocai$n e$, soutenue en 2000 à Liège en Belgique, est la somme de tous ses travaux réalisés sur une période de vingt ans.

Le livre analysé ici est justement tiré de sa thèse. L'auteur s'inspire toujours de ses connaissances du tourisme marocain, mais son traitement s'élargit au tourisme international. Il interroge, de son poste d'observation dans un pays du Sud, les grandes manœuvres des acteurs internationaux dans le tiers monde. Avant de relever les points forts du livre, un mot s'impose sur sa forme.

Le regard de Mimoun Hillali est unique : on le constate aisément à la seule lecture des titres et des sous-titres de sa table des matières. L'auteur a certes le sens de la formule, mais celle-ci sert d'abord le lecteur en le plaçant d'emblée devant des paradoxes, des contradictions, sinon des aberrations du système touristique. Cette manière d'exposer est stimulante pour l'esprit : elle permet d'accompagner l'auteur dans tout son parcours. Hillali est conscient qu'il n'y a pas de recettes miracles pour un développement touristique alternatif au Maroc. Il cherche inlassablement de nouvelles voies et si, parfois, il formule clairement quelques pistes de recherches, il invite le lecteur à chercher avec lui.

Hillali forme de futurs professionnels du tourisme ; il a pu voir de près les transformations qui s'opèrent quand on installe une nouvelle économie aux cotés de l'ancienne. Des changements en profondeur sur ce plan forcent des changements dans l'organisation sociale et la culture, mais ces derniers restent moins visibles ; ils agissent comme une vague de fond. Quand l'observateur les constate, ces changements semblent irréversibles et faire marche arrière devient une utopie. Reste alors à trouver des accommodations, des ajustements qui permettent de réduire les chocs entre les cultures anciennes et nouvelles, les conflits entre les institutions de jadis et celles d'aujourd'hui, etc. Les projets de développement doivent alors s'élaborer dans l'esprit d'une recherche du moindre mal... Hillali, pourtant, ne désespère pas face à l'avenir.

Pour autant, un pays comme le Maroc ne réunit pas toutes les conditions pour absorber sans effets collatéraux les changements dont le rythme s'accélère. Pour faire siennes les nouveautés, il faut avoir des aptitudes au changement. Dans nos sociétés développées, l'information abonde sans trop de censure, il y a place pour la discussion ; les idées neuves peuvent pénétrer graduellement et être digérées à des rythmes différents selon les groupes et les individus. Les idées et les valeurs nouvelles - et les attitudes et les habitudes qui les accompagnent se répandent bien difficilement dans les cultures des sociétés en développement où les institutions démocratiques restent souvent embryonnaires.

C'est dire que les peuples du Sud n'ont pas les meilleures conditions possibles pour inventer leur propre modernité en y intégrant les vagues de changements provoquées par les nouvelles réalités du monde du travail et, très particulièrement, de celui du tourisme. On peut ainsi comprendre l'énorme difficulté à imaginer l'avenir, à entrevoir simplement des voies différentes comme celles du tourisme social, du tourisme durable, du tourisme culturel. Les analyses de Mimoun Hillali nous placent devant ces difficultés comme peu d'écrits l'ont fait à ce jour ; nous sentons avec lui l'épaisseur des obstacles à franchir, la masse des résistances à vaincre.

Pourtant, son pays a franchement ouvert son territoire au tourisme depuis plus d'un demi-siècle ; le Maroc a fait l'expérience des plans triennaux ou quinquennaux, des recherches et des avis des grands bureaux d'études étrangers, des politiques favorables aux investisseurs extérieurs, des programmes d'aide au développement patronnés par les grandes instances internationales et des investissements massifs de l'État. Or, toutes ces interventions passées n'ont pas donné les résultats attendus, même sur le strict plan du marché des devises et de la création d'emplois. Maintenant que l'État se retire et privatise, les agents du tourisme international ont toute la latitude voulue pour introduire 


\section{LE TOURISME NTEENATIONAL

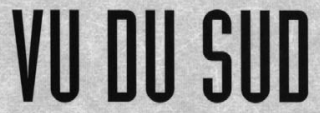

\section{Essai sur la problématique du tourisme dans les paus en développenent}

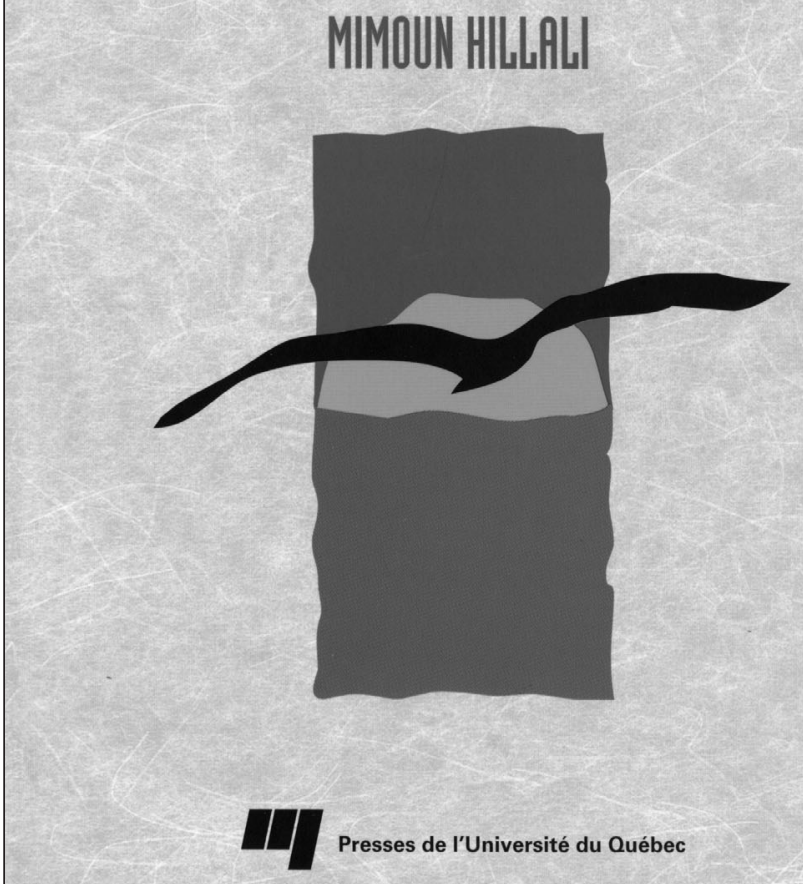

leurs capitaux comme leur mode de penser et de faire. Et, sur le plan mondial, la culture est devenue une vraie manne pour satisfaire les désirs inassouvissables de produits touristiques nouveaux.

Dans le chapitre clé du livre consacré aux rapports entre les espaces culturels et les espaces touristiques (chapitre 4), Hillali a pleinement conscience de l'ensemble de ces contraintes lourdes sur le futur du tourisme dans son pays. Il garde le cap sur un tourisme d'échanges interculturels, qu'il croit toujours réalisable, mais il hésite souvent et, à ce propos, il écrira qu'il s'agit peut-être d'une utopie possible : un droit de rêver, en fin de compte. À la lecture de ce chapitre, on comprend mieux comment d'autres auteurs ont sombré dans le pessimisme et se sont complu à dénoncer les ravages du tourisme international et des sociétés transnationales qui le gouvernent. Hillali évite ce piège, mais, derrière ses formulations quelquefois byzantines, nous devinons qu'il pourrait aller jusqu'à la dénonciation.

Par exemple, l'auteur montre les pièges de l'utilisation du patrimoine à des fins touristiques. Le processus par lequel on trans- forme en patrimoine les ressources culturelles et l'histoire est identique à celui de la sacralisation touristique ; avec, en prime, le fait que la marchandisation porte sur l'âme d'un peuple, sur sa mémoire, sur son héritage. S'il y a risque d'aliénation en tourisme, c'est sûrement par la touristification du patrimoine. Or, dans les sociétés en développement, ce sont souvent les agents touristiques qui s'empressent de récupérer le patrimoine à leurs fins et à leur manière, car, sur place, les priorités, tout comme les possibilités, sont ailleurs.

Et la tendance de fond des touristes internationaux d'aujourd'hui consiste justement à aller plus loin que le sightseeing, que les festivals, les carnavals et les fêtes organisées pour eux : on constate une demande accrue de séjours dans des familles typiques, d'accès à des lieux, des rituels, des cérémonies non accessibles aux étrangers, etc. Cette tendance est dans la logique de la recherche de l'exotisme : après le décor, son envers ; après l'apparence extérieure des choses et des gens, les paliers en profondeur ; après les places publiques, les lieux intimes ; après l'évidence, le mystère des choses cachées ; après la staged authenticity (MacCannell), l'informel, le non organisé, la spontanéité et, donc, l'authenticité.

Mimoun Hillali sent cette tendance, mais son optimisme l'incite plutôt à voir ces phénomènes comme des signes d'un échange touristique possible, d'un rapport interculturel, d'un contact humain qui peut faire changer les préjugés et les stéréotypes. Voit-il suffisamment, par contre, comment ce type de relations est exigeant et éprouvant pour les gens et la société qui reçoivent des visiteurs vacanciers ? Le Maroc n'a peut-être pas encore été envahi par ces nouveaux touristes ; les différences entre les cultures locales et celles des visiteurs sont encore si grandes qu'il suffit peut-être d'afficher son patrimoine pour intéresser les touristes ; enfin, le tourisme marocain a surtout été de type enclavé jusqu'à ce jour (stations balnéaires, villes impériales, etc.). Mais toute pensée sur le futur du tourisme ne peut pas ignorer les nouvelles attentes des visiteurs.

Marocain issu d'une famille berbère nomade, Mimoun Hillali est inépuisable quand il nous parle de son pays et nous entraîne à le visiter, quand il nous fait connaître son histoire, ses gens et leur vie quotidienne. Son livre est un vrai guide pour apprendre les réalités du tourisme dans un pays du Sud ; nous comprenons surtout que l'initiative et l'approche du développement touristique ne peuvent appartenir qu'aux pays qui reçoivent des touristes.

Marc Laplante, sociologue, est professeur à la retraite de l'Université du Québec à Montréal. Il a rédigé la préface du livre de Mimoun Hillali. 